\title{
Research on the Innovation of Teaching Assessment Model of Hotel Management Major Courses
}

\author{
Yinyan Zhang \\ Tianjin Maritime College, Tianjing, 300500
}

Keywords: Hotel management; course teaching; innovative mode

\begin{abstract}
China's domestic higher vocational education reform has achieved many gratifying results. However, most vocational colleges adopt a more traditional approach to curriculum assessment, which makes education reform unable to be further advanced. In order to meet the needs of modern teaching reform, we began to build an assessment system that focuses on competency assessment, and achieved good results through practice. This paper analyzes the problems existing in the traditional assessment methods, the guiding ideology and principles of the reform of the "Hotel Management" professional curriculum assessment method, from the professional curriculum process assessment, to the qualification examination, the speech draft form, the topic paper form, and the research report form. This paper analyzes and discusses the reform practice of the examination methods of professional courses, aiming to provide a certain theoretical basis for the reform of the assessment mode of hotel management courses.
\end{abstract}

\section{Introduction}

The traditional examination of higher vocational courses is mainly done by written test. The basis of the assessment is the results of the face and the coursework. The scores of the students are assessed through the set score standards. This method has great defects and cannot be allowed. The true level of professional skills is reflected, and in the daily education, students also develop mechanical learning habits, which is very unfavorable for students to improve their skills in the future.

The reform of college construction in China is constantly deepening. With the changes of the big environment, higher vocational education needs to rebuild its own training mode. Higher vocational colleges need to focus on practical work and build a reasonable curriculum system and action orientation for students. Nowadays, through practical trials, gratifying results have been achieved. The reforms in the "Hotel Management" of higher vocational education are constantly advancing, and the research and development of new evaluation methods has become a future development trend. However, how to make the assessment method reflect the professional ability level of the students is still a difficult problem that the hotel professional needs to overcome.

\section{The problems of the traditional theoretical test paper assessment of hotel management profession}

\subsection{Lack of procedural evaluation}

Before the reforms, the hotel's professional assessment of students was mainly based on written examinations, but not enough attention to the daily learning of students, which led to the school can not see a student's true level of knowledge.

\subsection{The assessment method is relatively simple and lacks pertinence}

Although the professional courses set up in higher vocational colleges revolve around the core skills, the traditional assessment mode lacks skill test items, and the content of the assessment is also very simple. It is impossible to effectively assess the students' ability according to the teaching content. The traditional assessment criteria are not comprehensive and have a large randomness. 
Teachers usually give students a grade based on their impressions, and they are also very vague in terms of scoring standards.

\subsection{The evaluation subject is single and the evaluation angle is limited}

The final result of the student's grade assessment is largely influenced by the teacher. The teacher sets up the course professor and then develops the assessment content himself. This leads to the limitation of the final assessment angle, which cannot fully reflect the student's learning effect.

\section{Guiding ideology and principles for the reform of the assessment methods for professional courses in "Hotel Management"}

\subsection{Guiding ideology}

According to the contents of the "Opinions on Improving the Teaching Quality of Higher Vocational Education in an All-round Way" issued by the Ministry of Education, it can be seen that the most important task in the reform of higher vocational education personnel training is to focus on open, professional and practical curriculum teaching. Internship, experiment, and training in the teaching process are very important key links. In the teaching process, the content of the course should be consistent with the actual work requirements. The assessment of the performance of the students in the school should be combined with the practice evaluation of the enterprise. Through the reform, the teaching mode of the course content and practice learning integration should be explored. Therefore, firstly, the orientation of work areas, standards, tasks, and training objectives should be clarified. In the process of teaching, students should focus on improving their professional ability and accomplishment. Adaptability is the future direction of education reform. Scientific standards should be set in the process of education. The result should be able to fully reflect the student's staged learning effect [1].

\subsection{Basic principles}

In accordance with the educational reform requirements that highlight professional ability, higher vocational colleges should focus on the following aspects: First, it is necessary to improve students' professional ability and practical application ability based on the actual post salary task content. The professional competence requirements of the post also include the ability of teamwork communication and learning. Secondly, the professional quality is demonstrated in the process of completing the salary of the post. Here, the professional quality, morality and integrity awareness are included.

The characteristics of vocational education itself will play a decisive role in the evaluation criteria. In the assessment of higher vocational colleges, not only must the practical experience be reflected, but also the mastery of theoretical knowledge. In the process of education, it is necessary to ensure that the teaching content and the actual post work content are consistent, so that the knowledge acquired by the students is converted into actual work benefits.

Formative evaluation refers to the assessment of the whole learning process of students in the process of education. According to the specific teaching focus and content of the course, students should be subdivided, and certain scores should be set by the importance of different factors. This approach allows students to increase their participation in the curriculum. The importance of summative evaluation is to assess the learning effect. This assessment is mainly for students' ability to improve after teaching. It is best to use a variety of methods when conducting this evaluation. Through organic integration in two ways, students can improve their courses. Participation in education.

The new curriculum reform not only weakens the dominant position of the teaching of the class, but also improves the subjective position of the students in education. Under this change, the evaluation method should also be adjusted by certain standards, and the students should be adjusted by adjustment. Evaluation, teacher evaluation, and group evaluation achieve an organic combination, so that students' learning effects are better reflected. 
Relevant teachers of the off-campus training base are required to evaluate and evaluate the performance of the students in the actual work, and comprehensively evaluate the students' skills mastery through the combination of off-campus and on-campus.

\section{The practice of the reform of the assessment method of the professional course of "Hotel Management"}

The "Hotel Management" major starts from the perspective of comprehensive assessment, and clarifies the content of the assessment and the ideas of reform: based on improving students' interest in learning, cultivating and improving students' professional ability and accomplishment in the teaching process, and making assessments through improvement and adjustment. The way is more diverse and flexible.

In the assessment process, the evaluation method is more diversified. The assessment of the theoretical course performance needs to be reported after the discussion by the teaching and research group, and then it can be implemented. The assessment method can be more targeted according to the characteristics of the course, such as unit test and task-driven assessment. Education assessment plays a guiding role in the whole education process. The scientific and reasonable assessment system can greatly improve the quality and effect of education. Therefore, it is necessary to change the traditional single written examination evaluation, and to target the students in the course education. Sexual assessment, and then summarize the assessment results to give a comprehensive evaluation, which will allow students to pay more attention to daily assessments to prevent pre-exam preparations.

"Certificate for the test" refers to the national vocational qualification test instead of the course completion test. Under the current economic development situation, talents need to master more professional skills and solid basic operations. Under such an era, schools need to deliver more high-end skilled talents to the hotel industry. At present, domestic college education is enhancing students' double-certificate rate, and reforming the assessment system through gradual changes.

The "test-and-test" model allows students to better define their learning goals and build a better learning atmosphere. The traditional final exams are usually performed by the instructors, which leads many students to take the exams in a normal way. They will not be able to fully grasp the curriculum knowledge and understand the knowledge. A large deviation occurred. Teaching in the class should conduct an in-depth study of the syllabus and adjust to improve the teaching methods. Schools should build a more comprehensive team of teachers, so that education and assessment should be separated, and the assessment should be more fair and objective.

The assessment method in the form of speech can improve the students' thinking quality and improve the students' oral expression ability, which will greatly help students' future career development and job problems.

At present, most teachers still use papers as a way of final assessment. Many courses use this method as the only assessment standard. This kind of assessment method can enable students to get certain research training, stimulate students' creativity, and improve students' theoretical learning ability and thinking ability. Of course, this kind of assessment method also has certain defects. If you want to improve the assessment form of the paper, you need to develop strengths and circumvent weaknesses according to the characteristics of this assessment method, and make up the defects through reasonable improvement. On the basis of continuously improving the types of assessment forms, Set the number of periodic papers to be completed. In the paper writing stage, students should be given sufficient time to think about the students' choices.

Through the form of research report assessment, students will actively collect relevant literature, journals, etc. related to hotel management in journals, newspapers, etc., students can gain certain theoretical knowledge application experience through active collection and reading, and will cultivate their own Innovation and learning ability; through this learning method, students' ability to solve and analyze problems can be improved to some extent [2]. 


\section{Conclusion}

In the ongoing education reform, we must constantly explore the research, find ways to improve the teaching effect of hotel management, and build a perfect talent evaluation system, which will not only have a direct impact on the curriculum construction. At the same time, it will also promote the innovation of talent training methods and the realization of educational goals. The cultivation of learning ability is far more important than the accumulation of theoretical knowledge. Therefore, in the process of assessing students, it is necessary to continuously optimize the existing assessment methods through reforms. Higher vocational colleges have carried out professional practice model innovations, not only to improve the quality of teaching, but also to allow students to actually work. The ability has been improved, which will greatly promote the future employment of students.

\section{References}

[1] Zhai Hongxia, Lin Xiangjun, Zhang Yunxia. Exploration and Reflection on the Reform of the Assessment Method of Professional Courses in Hospitality Management in Higher Vocational Education[J]. Journal of Liuzhou Vocational and Technical College, 2008, 8(3): 55-57.

[2] Du Fang. Research on the Current Situation and Countermeasures of Curriculum Development in Higher Vocational Hotel Management[J]. Journal of Hunan Industrial Polytechnic, 2011, 11(1): 123-125. 